\title{
CDISC Classifier Role
}

National Cancer Institute

\section{Source}

National Cancer Institute. CDISC Classifier Role. NCI Thesaurus. Code C142414.

Classifier for variables that describe observations in the SDTM. Role is a metadata attribute that determines the type of information conveyed by an observation-describing variable and standardizes rules for using the describing variable. (CDISC) 